\section{FREQUENCY OF PENICILLIN-RESISTANT STAPHYLOCOCCI}

\author{
BY
}

\section{A. VOUREKA, M.D.}

AND

\section{W. HOWARD HUGHES, M.D.}

(From the Wright-Fleming Institute of Microbiology, St. Mary's Hospital, London, W.2)

Because of the large number of strains which are now grossly resistant to penicillin statements have been made that the drug is losing its value in staphylococcal infections. There was reason to believe that the number of resistant strains had been exaggerated, so an investigation was undertaken to ascertain the sensitivity to penicillin of staphylococci taken at random from out-patients.

The patients were those attending our asthma clinic and they were not at that time suffering from obvious staphylococcal infections. There was no risk of cross-infection, as they were swabbed on their first attendance and came from widely separated areas of the country. The strains were collected between January and June, 1948.

Swabs were taken from the anterior nares and cultivated on blood agar from which a number of single colonies were selected from each positive swab. By the appearance of the colonies and by the presence or absence of haemolysis and of coagulase production, 315 distinct strains were selected from 241 patients. Of these, 191 were albus, 121 aureus, and 3 citreus. There were 185 coagulase-positive strains and 119 coagulase-negative (11 strains were not tested). All were tested for sensitivity by the ditch-plate method as originally described by Fleming and Allison (1922). The strains to be tested were streaked on either side of the ditch and compared with the standard Oxford strain planted at the same time. A strength of $\mathbf{1 0}$ units of penicillin per $\mathrm{ml}$. was used in the ditch. After overnight incubation the zone of inhibition between the edge of the ditch and the edge of the growth was measured with callipers. The results obtained are shown in Table $I$.

TABle I.-Resistance to Penicillin of Staphylococci Taken at Random

\begin{tabular}{|c|c|c|c|}
\hline \multicolumn{2}{|c|}{ No. of Strains } & $\begin{array}{l}\text { Distance of Inhibition from } \\
\text { Penicllin Ditch }\end{array}$ & Remarks \\
\hline \multicolumn{2}{|c|}{$\begin{array}{c}\text { Standard } \\
\text { Oxford strain }\end{array}$} & $16 \mathrm{~mm}$. (average of all plates) & Standard control \\
\hline $\left.\begin{array}{l}55 \\
73 \\
75\end{array}\right\}$ & 203 & $\left.\begin{array}{c}16 \mathrm{~mm} . \\
\text { Standard } \pm 1 \mathrm{~mm} . \\
\#\end{array}\right\}$ & Regarded as the same as control \\
\hline $\begin{array}{l}1 \\
2 \\
1\end{array}$ & $\ddot{.}$ & 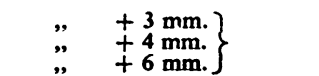 & More sensitive \\
\hline $\begin{array}{r}29 \\
30 \\
16 \\
3 \\
4\end{array}$ & 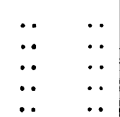 & 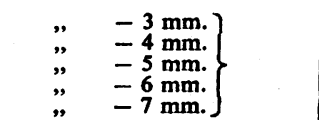 & Less sensitive \\
\hline 26 & .. & - over $7 \mathrm{~mm}$. & Provisionally classed as resistant \\
\hline
\end{tabular}

\section{Penicillinase Production}

On these figures, 26 strains may be provisionally classed as resistant ; 24 of these were tested for their power to produce penicillinase. The method employed was as follows :

The resistant strains were again planted on a ditch plate, similar to the one used before, with 10 units of penicillin per . ml. of agar in the ditch. On each side of, and as close as possible to, the resistant strains streaks of the standard Oxford staphylococcus were planted. At some distance a similar streak of the standard Oxford staphylococcus was planted as a control. Whenever the resistant strains produced penicillinase the ditch end of the Oxford staphylococcus streak had a slanted instead of a straight edge, with the protruding point nearer to the streak of the resistant staphylococcus. The streak was noticed to encroach on the zone of inhibition as incubation continued, creeping gradually nearer to the ditch.

It was thus found that 11 strains produced penicillinase and 13 did not.

\section{Titration of Resistant Strains}

Of these 26 apparently resistant strains, 16 grew to within $2 \mathrm{~mm}$. of the ditch and were regarded as definitely resistant, but it was decided to see exactly what concentration of penicillin would be tolerated by the remaining 10 strains which showed zones of inhibition of from 3 to $8 \mathrm{~mm}$. from the ditch. The 10 strains were subcultured a few weeks after isolation, but unfortunately one failed to grow.

In testing the surviving nine strains dilutions of penicillin in broth from 12.5 units per $\mathrm{ml}$. to 0.02 unit per $\mathrm{ml}$. were used. The amount of the inoculum was 100 c.mm. of a 24-hour broth culture to $5 \mathrm{ml}$. of broth. The results are given in Table II. These show that of the 26 strains pro-

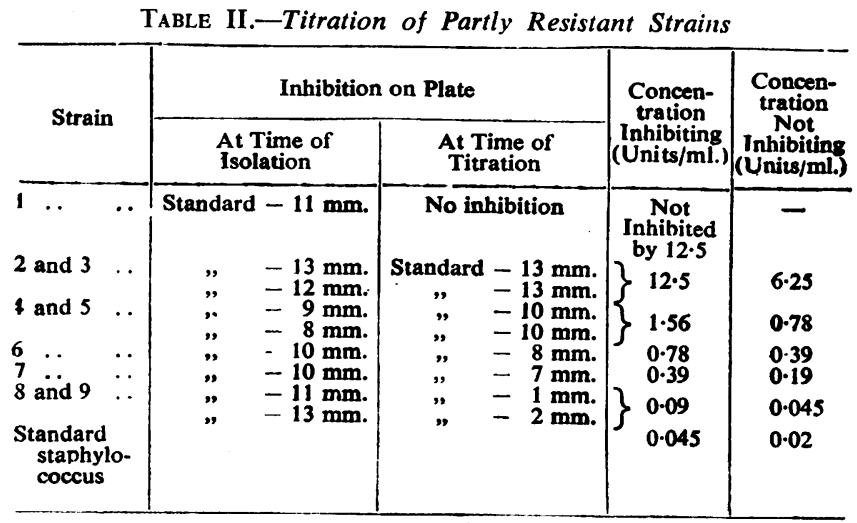

visionally classed as resistant, one was sensitive to 0.5 unit per $\mathrm{ml}$. and two to 1 unit. Two strains had recovered their sensitivity to penicillin and one had apparently become more resistant.

If we take resistance to 1 unit per $\mathrm{ml}$. as our arbitrary standard of a "resistant" staphylococcus, we have only 24 resistant strains out of 315 (including the two strains which in a few weeks acquired sensitivity and the one which died out)-that is, $7.6 \%$. These 24 strains had the following characters :

\begin{tabular}{c|c|c|c|c|c}
\hline \multicolumn{3}{|c|}{ Colour } & \multicolumn{2}{c|}{ Coagulase Test } & Not Tested \\
\hline Aureus & Albus & Citreus & + & - & \\
\hline 12 & 11 & 1 & 14 & 7 & 3 \\
\hline
\end{tabular}

The proportion of resistant strains appears to be independent of whether the strains are aureus or albus, or coagulase-positive or coagulase-negative.

\section{Summary}

In a survey of 315 distinct strains of staphylococci, only $7.6 \%$ were found to be resistant to 1 unit of penicillin.

\section{REFERENCE}

Fleming, A., and Allison, V. D. (1922). Proc. roy. Soc. B., 94, 142.

Housing associations provide residential accommodation for old people, and, though receiving financial help from local authorities, they retain the character of voluntary organizations. The National Old People's Welfare Committee has issued a useful pamphlet called "Why Housing Associations?" on how to start them, what their scope is, and who can help those interested in them. It is obtainable from the National Council of Social Service, 26, Bedford Square, London, W.C.1, for $6 \mathrm{~d}$. 